\title{
EFFECT OF STRAIN HARDENING CAPACITY ON FATIGUE LIFE OF STRUCTURAL STEEL
}

\author{
M. H. Seleem \\ Materials Engineering Department, Faculty of Eng., \\ Zagazig University, Zagazig, Egypt
}

\begin{abstract}
A single edge cracked panel subjected to monotonic and cyclic loading has been analyzed using two-dimensional elastic-plastic finite element program. The effect of strain hardening exponent on the stress-strain and the deformation behavior at the crack tip was studied at different maximum applied stress ranges. The analysis was performed for the plane stress state at constant amplitude loading of zero stress ratio. Relevant kinematic parameters corresponding to loading and unloading phases of a cycle were computed and correlated. Parameters controlling the fatigue life of the structural elements, i.e. plastically deformed zone and crack tip opening displacement were estimated and correlated.

The results indicated that with increasing the strain hardening exponent, the normal tensile stress decreases within the crack tip plastic zone while the normal tensile strain showed an opposite trend. Also the normal tensile stress tends to be constant inside the monotonic plastic zone at the higher values of the strain hardening exponent irrespective of the value of the applied stress range. The results also show that the crack tip opening displacement increases with increasing the strain hardening exponent, whilst the plastic zone showed an opposite trend. Those behaviors were analyzed for their correlation. A previously developed crack tip deformation parameter to correlate fatigue crack growth was modified to include the effect of strain hardening capacity of the material.
\end{abstract}

\section{KEYWORDS}

Finite element method; cyclic loading; strain hardening; crack tip plastic deformation.

Manuscript received from $\mathrm{Dr}$. M.H.Seleem

Accepted on : $25 / 3 / 2001$

Engineering Research Journal Vol 24,No 3, 2001 Minufiya University, Faculty of

Engineering, Shebien El-Kom , Egypt, ISSN 1110-1180 


\section{INTRODUCTION}

A number of highway and railroad bridge structures have experienced fatigue cracking which sometimes resulted in brittle fracture as a result of service loading $[1,2,3]$. The occurrence of fatigue failure in such structures is due to the existence of stressconcentration regions at the riveted or welded joints. A survey of serious accidents involving fatigue fracture clearly underlined the importance of such stress concentrators as crack initiation sites for fatigue life estimation of structural elements [4]

It is worth to mention that, the mechanical behavior of weld zone and heat affected zone is changed due to the welding procedures. One of the most properties that will be changed due to such effect is the strain hardening capacity of the material which defined by the exponent $\mathrm{n}$ in the relation controlling the behavior of the material in the plastic

range of the true stress-true strain diagram and defined by the equation $\sigma_{t}=b \varepsilon_{t}^{n}$, where $b$ is the strength coefficient.

The analysis of fatigue crack growth (FCG) rates should make use of the parameters related to its mechanism. Analyses of some two dimension (2-D) problems proved the ability of crack tip deformation (CTD) to predict fatigue behavior of long cracks under constant and variable amplitude loading $[5,6]$ and of physically short cracks under constant amplitude loading [7]. Those works prove that the crack tip opening displacement (CTOD) is a good representative of CTD since it reflects the integration of the plastic strain field over the crack tip plastically deformed zone (CTPDZ) [7]. Although such deformation is greatly influenced by the change in the mechanical properties of the material, the effect of changing the strain hardening exponent, $n$, of the material on such deformation is not included through such parameter. The effect of strain hardening capacity on the plasticity induced fatigue crack closure was studied by Llorca and Sanchez [8] by using a finite difference program applied to a center-crack panel. Linear strain hardening behavior was assumed in this analysis. The main objective of the present work is to study the effect of strain hardening exponent on stress-strain field and deformation parameters generated at the tip of a single edge cracked panel.

\section{NUMERICAL PROGRAM}

An elastic-plastic model for 2-D finite element analysis previously developed by Hammouda and Sallam [5] was utilized to simulate effect of strain hardening exponent on the stress-strain and deformation behavior at the tip of a cracked panel as a result of a constant amplitude pulsating axial load. The Von-Mises yield criterion and the PrandtlReuss flow rule were adopted. To simulate the Baushinger effect associated with reversed yielding, the kinematic hardening model as described by Ziegler [9] was employed. The panel was stressed firstly by a monotonic loading followed by the unloading and reloading phases of the stress cycle which was repeated until the achievement of a stable hysteresis loop in terms of CTOD against the applied load. In the plastic regime, the stress-plastic strain behavior of the material was assumed to obey a simple power law. 
During the excursion of each phase of the cycle, the deformation and the stress state around the crack tip were incrementally traced.

A panel of a width, $w$, of $50 \mathrm{~mm}$ and a height, $\mathrm{h}$, of $150 \mathrm{~mm}$ having a single edge crack of a length $\ell$ such that $\ell / \mathrm{w} \cong 0.5$ was used. The material was typically of a structural steel with a modulus of elasticity, $\mathrm{E}$, of $206 \mathrm{GPa}$, Poisson's ratio of 0.3 , yield stress, $\sigma_{\text {yield }}$, of $350 \mathrm{MPa}$, strength coefficient of 1100 , and different $\mathrm{n}$ ranges between 0.1 to 0.7 . The panel was analyzed in the plane stress condition with stress ratio $\mathrm{R}\left(=\sigma_{\min } / \sigma_{\max }\right)$, equals zero according to the program presented in Table 1.

Table 1. Numerical program suggested for the present work

\begin{tabular}{|l|c|c|c|c|c|c|}
\hline Strain hardening exponent, $\mathrm{n}$ & 0.10 & 0.15 & 0.20 & 0.30 & 0.50 & 0.70 \\
\hline Applied stress range, & 20,24 & 20,24 & 20,24 & 20,24 & 20,24 & 20,24 \\
$\Delta \sigma\left(=\sigma_{\max }-\sigma_{\min }\right), \mathrm{MPa}$ & 28,32 & 28,32 & 28,32 & 28,32 & 28,32 & 28,32 \\
\hline
\end{tabular}

Due to symmetry, only one half of the panel was modeled. Three node constant strain triangle elements were used. A small element size to accurately capture both the monotonic and cyclic plastic deformation existing around the crack tip could be realized. The crack tip was located in the fine mesh region. The smallest element size near the crack front was generally $0.0625 \mathrm{~mm}$. The geometry of the used panel and the finite element idealization in the present work is shown in Fig. 1.

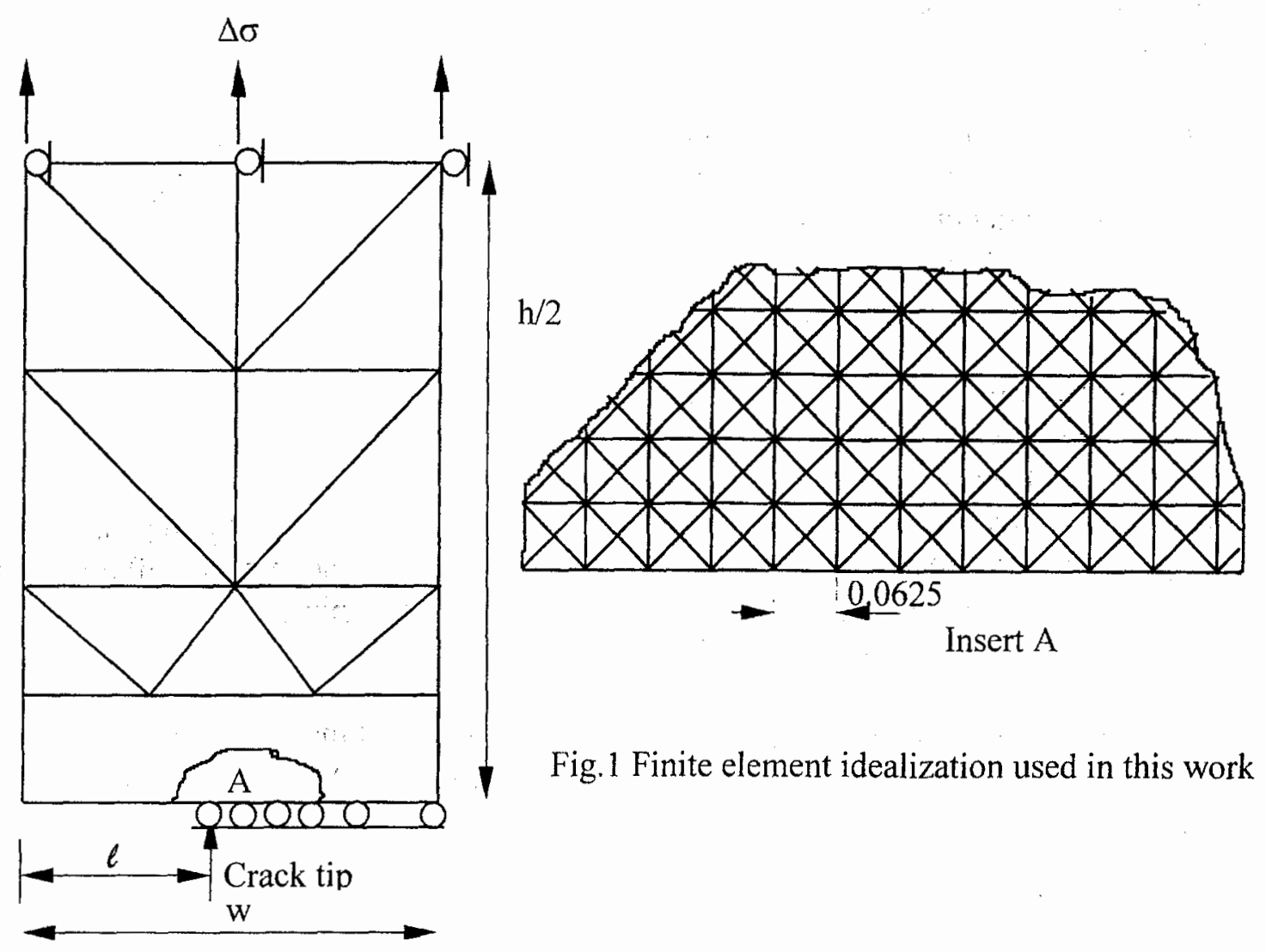




\section{RESULTS AND DISCUSSION}

The behavior of normal tensile strain, $\varepsilon_{y y}$, and normal tensile stress, $\sigma_{y y}$, ahead of the crack tip is shown in Fig. 2 for different strain hardening exponent, $\mathrm{n}$, and at applied stress range, $\Delta \sigma$, of $24 \mathrm{MPa}$. The stresses and strains were calculated at the center of each brick element ahead of the crack tip as the average value in the four triangular elements comprising that brick.

The figure illustrates that the maximum value of $\varepsilon_{y y}$ is occurred near the crack tip. Away from the crack tip, $\varepsilon_{y y}$ decreased rapidly within the extension of the plastic zone on the horizontal direction ahead of the crack tip. On increasing $n$, a marked increase in $\varepsilon_{y y}$ is observed up to $n$ equals 0.3 above which, the effect of increasing $n$ on the normal tensile strain is small. Out side the plastic zone, $\varepsilon_{y y}$ is nearly constant and did not depend on the value of $n$, elastic behavior.

On the other hand the normal tensile stress $\sigma_{y y}$ showed an opposite trend for the effect of strain hardening exponent. The figure shows that $\sigma_{y y}$ decreases with $\mathrm{n}$ increases up to $\mathrm{n}$ equals 0.3 after that no effect is recorded for further increase in $n$ irrespective of the value of the applied stress as shown in Fig. 3. Figure 3 shows also that at higher values of $n$, the normal tensile stress is approximately constant inside the crack tip plastic zone. Out side the plastic zone, elastic region, $\sigma_{y y}$ decreases on increasing the distance from the crack tip.
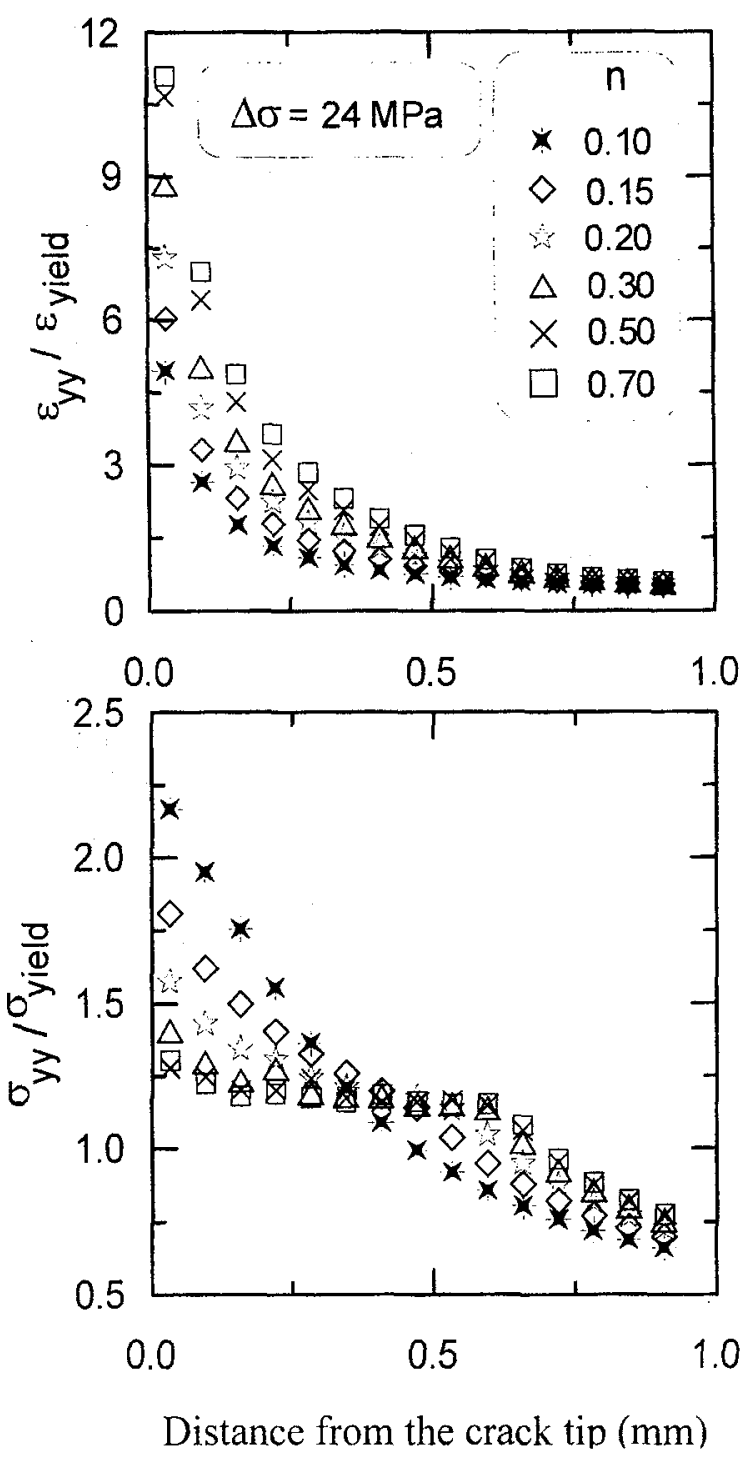

Fig. 2 Variation of $\varepsilon_{y y}$ and $\sigma_{y y}$ ahead of the crack tip for different strain hardening exponent

The effect of strain hardening exponent on the development of the size of the plastic zone generated at the end of the monotonic loading (MCTPZ), $\Delta_{\mathrm{m}}$, is shown in Fig 4. The extent of $\Delta$ was calculated as the diameter of a circle having the same area as the plastically deformed elements. 

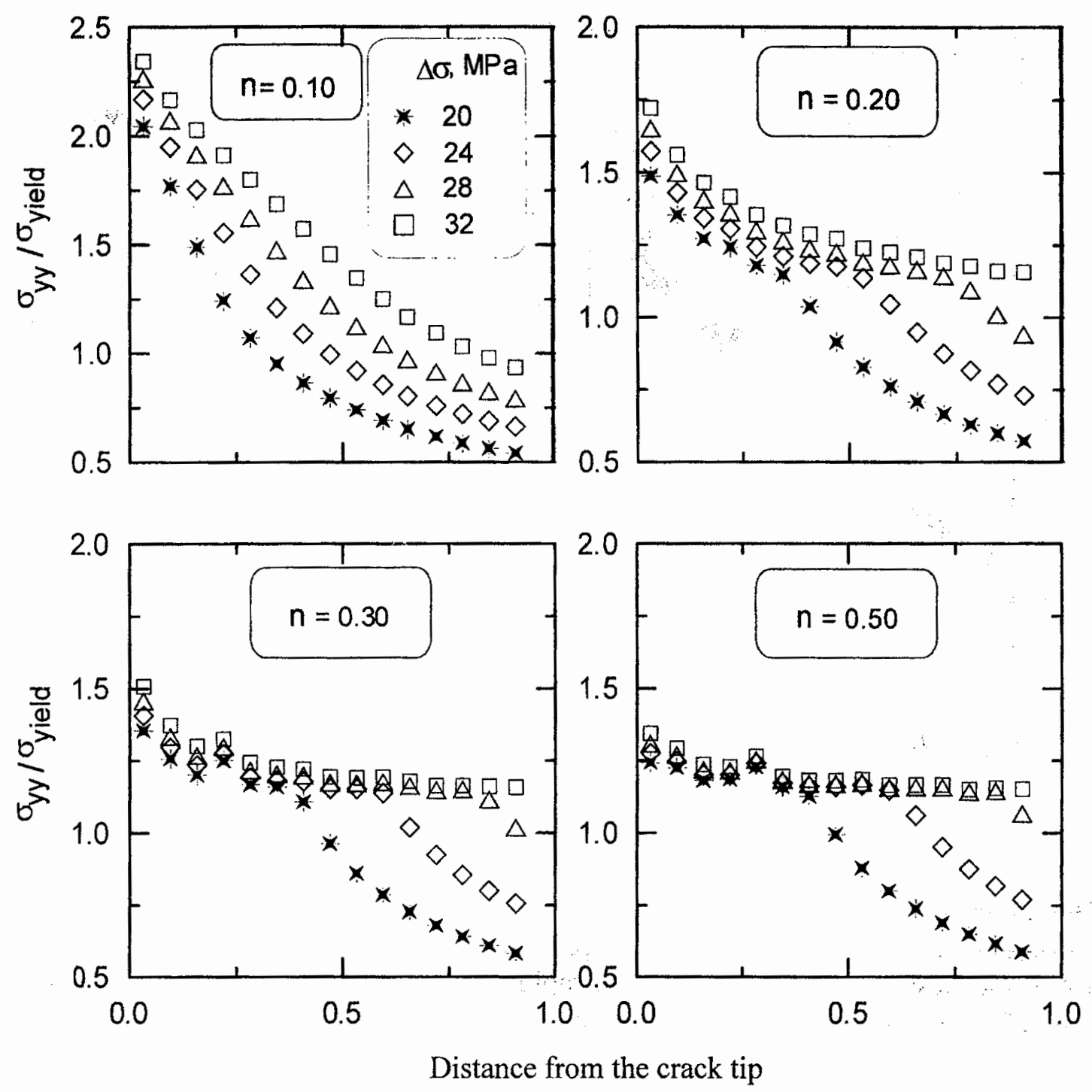

Fig. 3 Effect of applied stress on the variation of the normal tensile stress ahead of the crack tip at different strain hardening exponent.

The figure illustrates a general increase in $\Delta_{\mathrm{m}}$ with increasing the applied stress with an increasing rate. With increasing the strain hardening exponent, the monotonic plastic zone decreases. The present results were used to correlate $\Delta_{\mathrm{m}}$ in terms of the applied stress, $\sigma$, material yield strength, $\sigma_{\text {yield, }}$ specimen geometry, $\mathrm{Y}$, and strain hardening exponent, $\mathrm{n}$, to the form presented in Fig. 5. The following relation was suggested:

$$
\Delta_{\mathrm{m}}=2.15 \odot \mathrm{Y}^{2} \ln \sec (\beta \sigma) \mathrm{n}^{\alpha}
$$

Where $\mathrm{Y}$ is the specimen geometry correction factor, $\alpha$ is constant equals $-0.06, \beta=\pi / 2 \mathrm{~T}$ and $T$ is the flow stress which equals $2 \sigma_{\text {yield. }}$ 


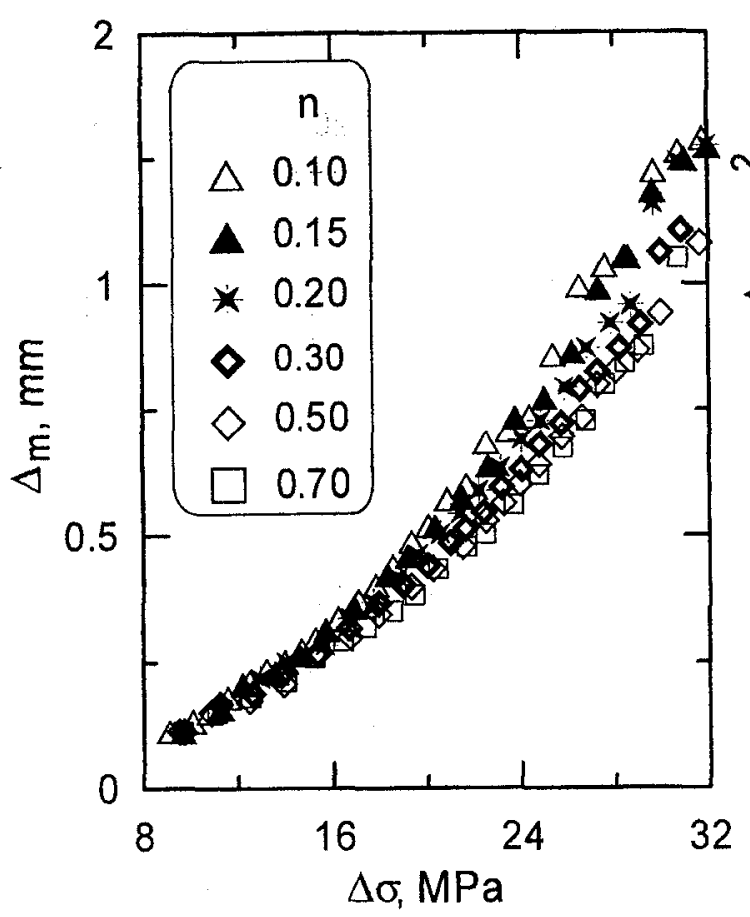

Fig. 4 Development of $\Delta_{\mathrm{m}}$ with the applied stress

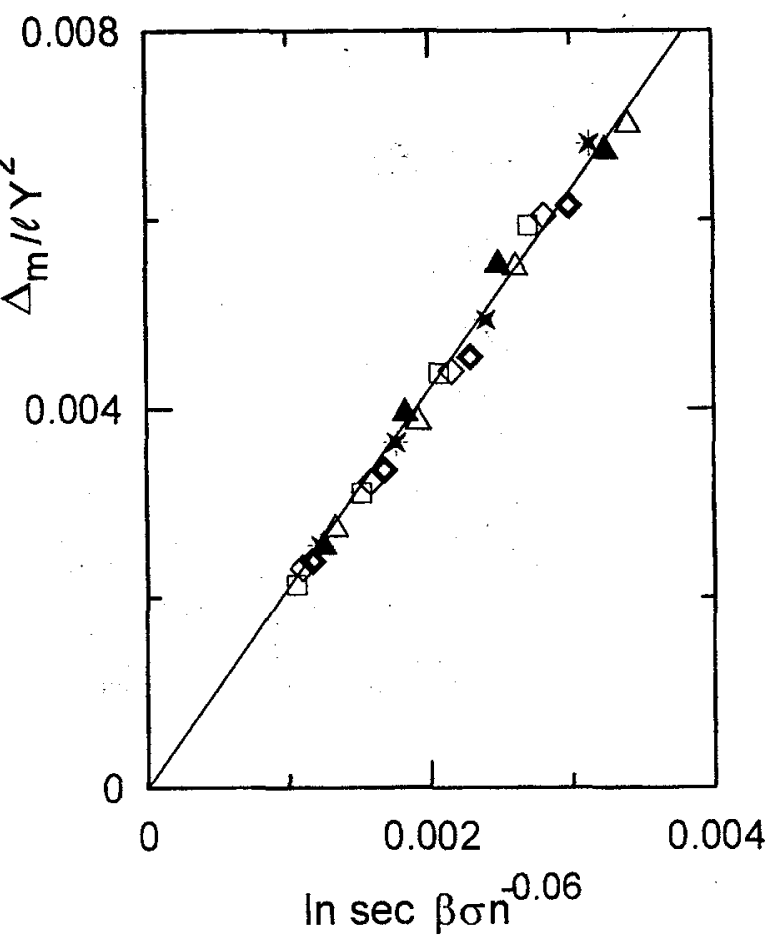

Fig. 5 Correlation of $\Delta_{\mathrm{m}}$ with the applied stress

The effect of strain hardening exponent on the shape of monotonic plastic zone is illustrated in Fig. 6 for applied stress range of $28 \mathrm{MPa}$. Its obvious that for lower value of $\mathrm{n}=0.1$, the plastic zone is developed more rapidly in the upward direction, whilst at higher $\mathrm{n}, \mathrm{n}=0.7$, its extension is more in the forward direction ahead of the crack tip.

The extent of the cyclic crack tip plastically deformed zone (CCTPZ), $\Delta_{\mathfrak{c}}$, was given by the plastically deformed elements commonly generated at maximum re-loading and minimum un-loading. The effect of the strain hardening exponent on $\Delta_{\mathrm{c}}$ is demonstrated in Fig. 7.

The figure shows a general decrease in $\Delta_{c}$ with increasing $\mathrm{n}$. This effect is relatively small at higher values of $n$. The present data for $\Delta_{c}$ were used for its correlation with the applied stress range, specimen geometry, material cyclic yield stress, $\sigma_{c y}$, and strain hardening exponent as shown in Fig. 8. The following relation was best fitted:

$$
\Delta_{c}=\ell Y^{2} \operatorname{lnsec}(\beta \Delta \sigma) n^{\alpha}
$$

Where $\alpha$ equals $-0.06, \mathrm{~T}=2 \sigma_{\mathrm{cy}}$, and $\sigma_{\mathrm{cy}}=2 \sigma_{\text {yield }}$ 

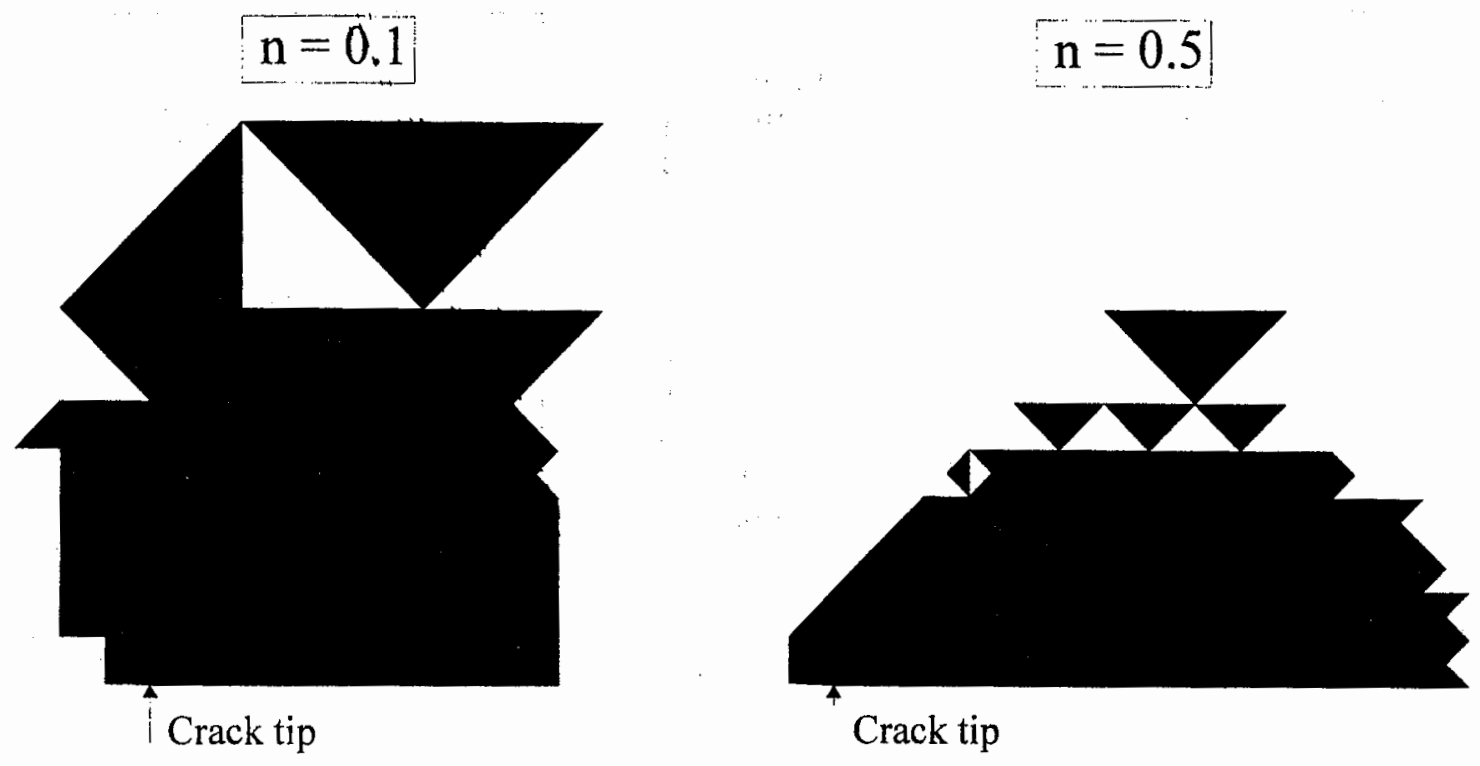

Fig. 6 Monotonic plastic zone shape for different strain hardening exponent

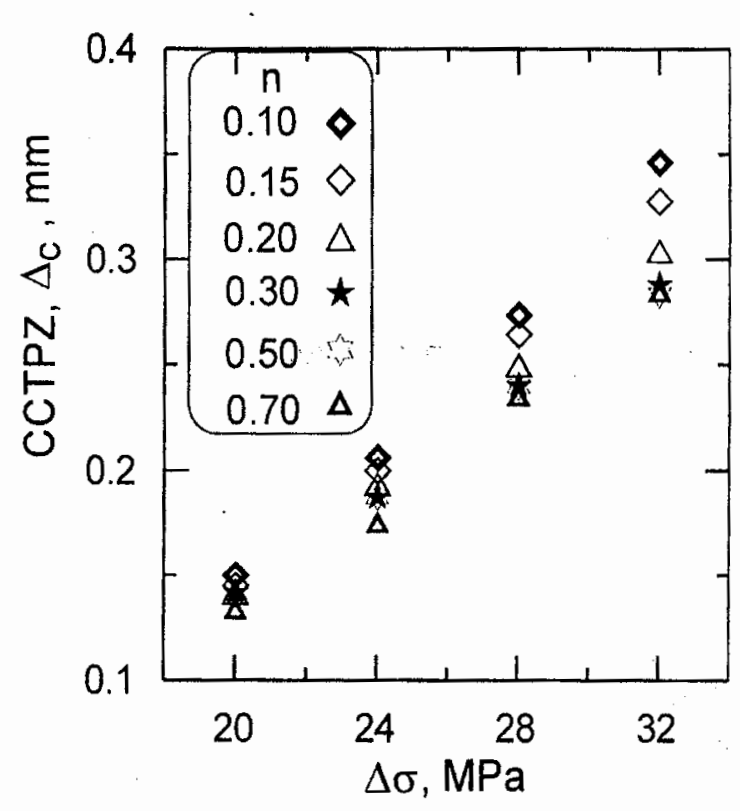

Fig. 7 Effect of strain hardening exponent on the cyclic plastic zone size

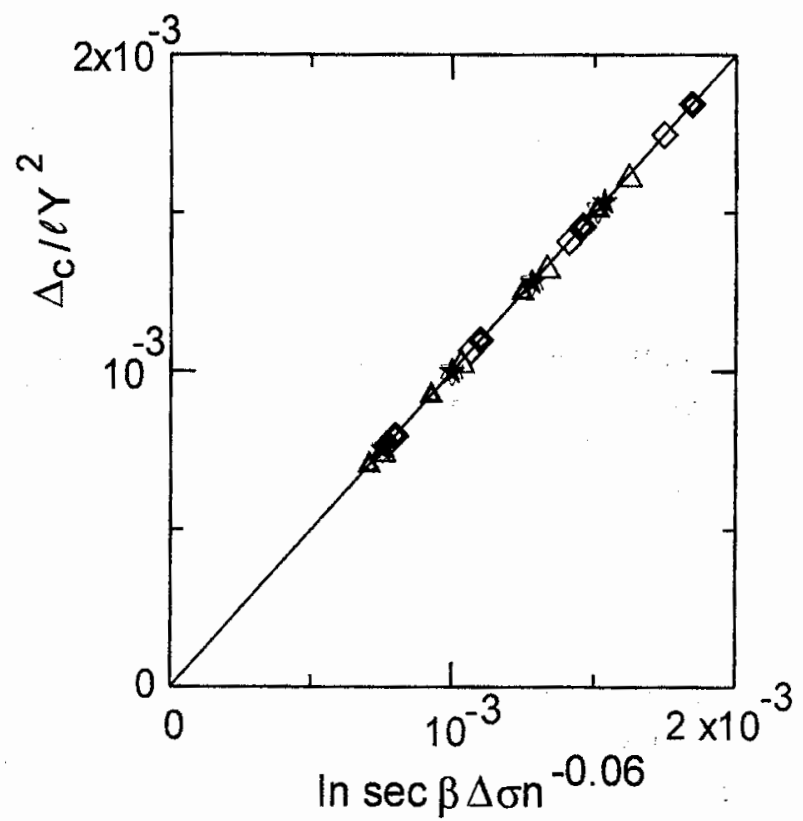

Fig. 8 Correlation of $\Delta c$ with the applied stress range

The relation between $\Delta_{m}$ and $\Delta_{c}$ for all cases studied in the present work is shown in Fig. 9. The figure shows that $\Delta_{\mathrm{c}} \cong 0.25 \Delta_{\mathrm{m}}$ which is in agreement with the ratio stated in linear elastic fracture mechanics analysis for zero stress ratio[10] 
The development of the maximum crack tip opening displacement, $\delta_{\mathrm{s}}$, with the applied stress for different strain hardening exponent is shown in Fig. 10. The CTOD is defined as the vertical displacement of the first node just behind the crack tip.

The figure shows that, $\delta_{s}$ increases with increasing the applied stress with an increasing rate and this is due to the development of plastic deformation around the crack tip. With increasing $n$, the CTOD increases with a decreasing rate and the effect is so much small at large values of $n$. The increase in $\delta_{s}$ with increasing $n$ is mainly due to effect of the generated normal tensile strain.

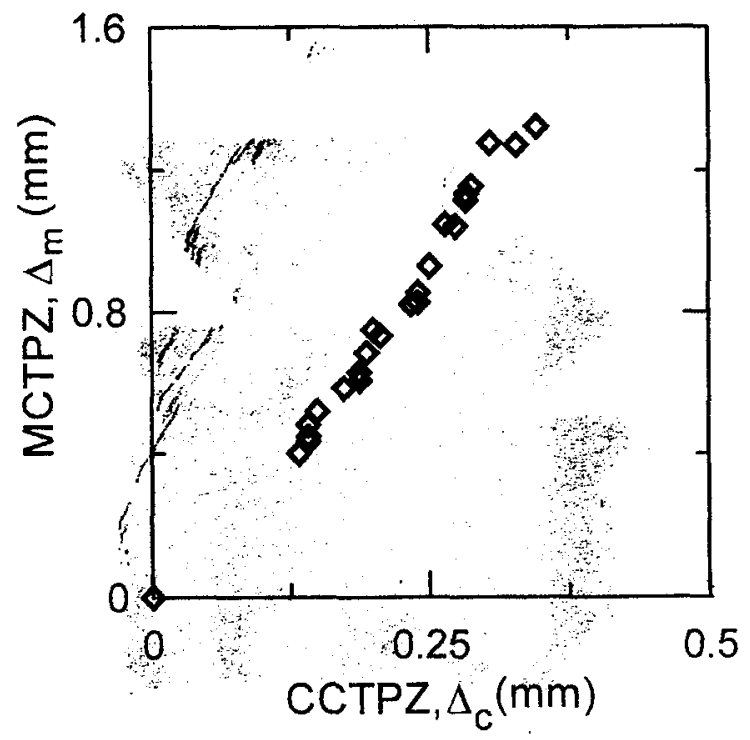

Fig. 9 The relation between $\Delta_{\mathrm{m}}$ and $\Delta_{\mathrm{c}}$

The CTOD is depicted in terms of the applied stress, mechanical behavior of the material, strain hardening exponent and specimen geometry as illustrated in Fig. 11. This data was used to best fit the following equation to predict $\delta_{s}$ in terms of the above parameters

$$
\frac{\delta_{\mathrm{S}}}{\mathrm{Y}^{2}}=\frac{2.2}{\mathrm{E} \beta}(\beta \sigma)^{\gamma} \mathrm{n}^{\alpha} \ln \sec (\beta \sigma)
$$

Where $\alpha$ equals 0.2 and $\gamma$ equals -0.42

Hammouda and Sallam [5] suggested a crack tip deformation parameter to correlate FCG data in the form

$$
\mathrm{CTD}_{\mathrm{p}}=\left[\frac{\delta_{\mathrm{s}}}{\delta_{\mathrm{r}}}\right] \frac{\Delta \delta}{\mathrm{Y}^{2}}
$$

Where $\delta_{\mathrm{s}}$ and $\delta_{\mathrm{r}}$ are the maximum CTOD of stationary and propagating crack respectively and $\Delta \delta$ is the cyclic CTOD. They suggested the following relations to estimate $\delta_{\mathrm{r}}$ and $\Delta \delta$

$$
\begin{aligned}
& \delta_{\mathrm{r}}=\delta_{\mathrm{s}}\left[1.778\left(\frac{\Delta_{\mathrm{c}}}{\Delta_{\mathrm{m}}}\right)\right]^{0.9} \\
& \Delta \delta=10.63 \delta_{\mathrm{s}}\left(\frac{\Delta_{\mathrm{c}}}{\Delta_{\mathrm{m}}}\right)^{1.545}
\end{aligned}
$$


for opened cracks, and

$$
\begin{aligned}
& \delta_{\mathrm{r}}=\delta_{\mathrm{s}}\left[0.95\left(\frac{\Delta_{\mathrm{c}}}{\Delta_{\mathrm{m}}}\right)\right]^{0.67} \\
& \Delta \delta=0.95 \delta_{\mathrm{s}}\left(\frac{\Delta_{\mathrm{c}}}{\Delta_{\mathrm{m}}}\right)^{0.67}
\end{aligned}
$$

for closed cracks

The strain hardening exponent is not included in the relations suggested by hammouda and sallam [5] for the estimation of $\delta_{\mathrm{s}}, \Delta_{\mathrm{c}}$ and $\Delta_{\mathrm{m}}$. Equations 2 and 3 are assumed for a propagating fatigue crack, while equations 5 to 8 can be re-estimated now based on equations 1 to 3 to include the effect of strain hardening exponent on the crack tip deformation. The CTD parameter can thus recalculated based on these new equations to include the effect of such important mechanical property.

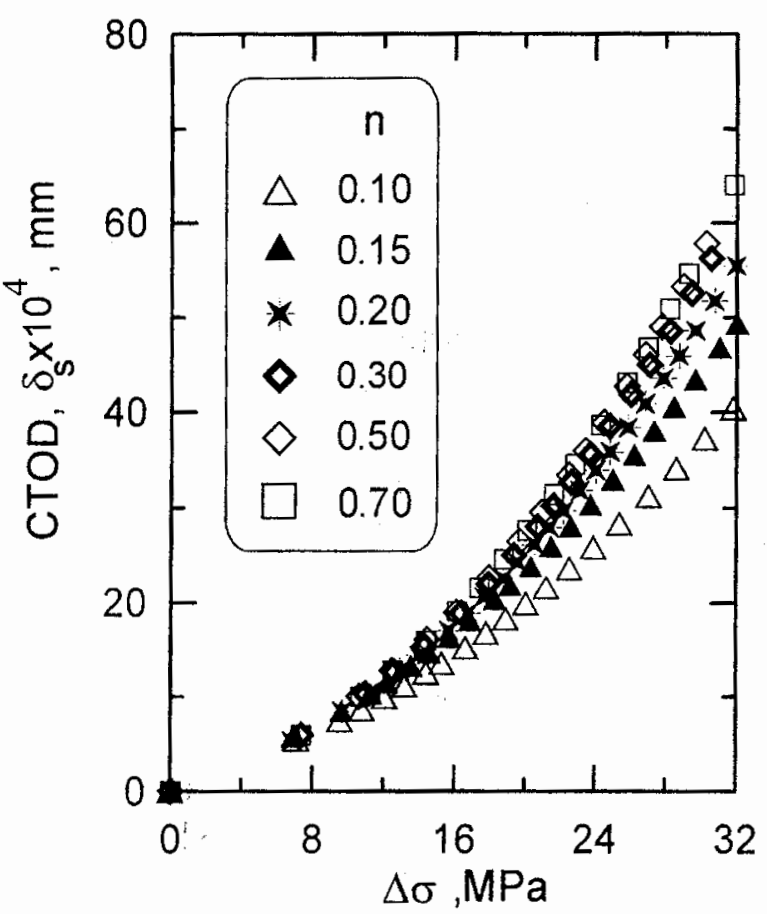

Fig. 10 Development of CTOD with the applied stress

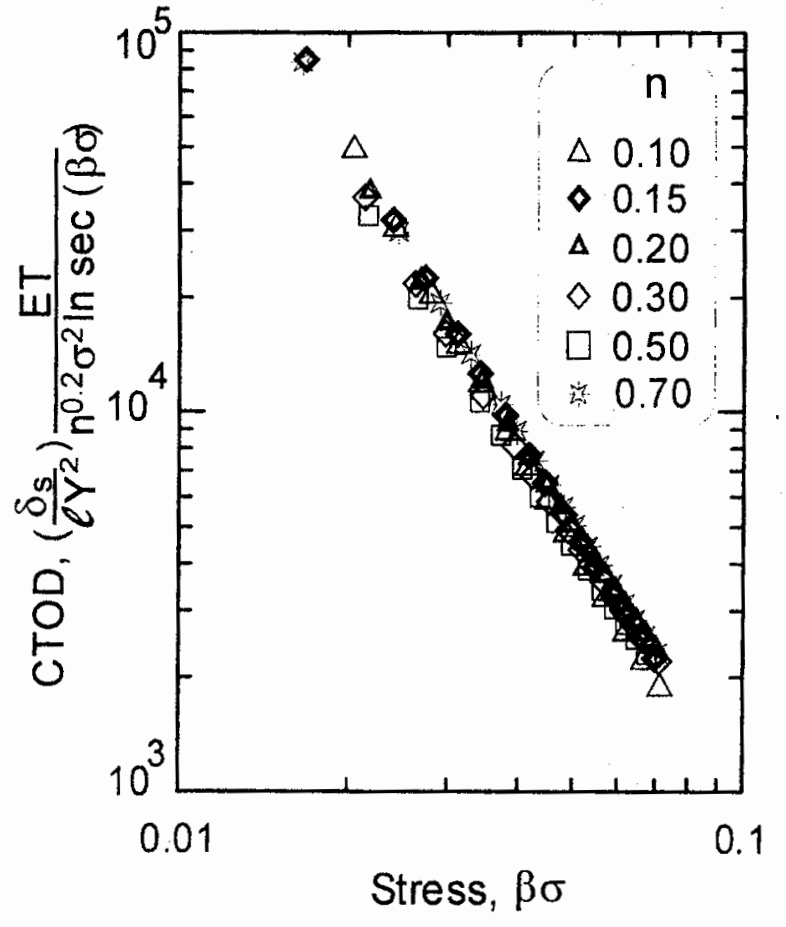

Fig. 11 Correlation of CTOD with the applied stress 


\section{CONCLUSIONS}

1. With increasing the strain hardening exponent, the normal tensile stress decreases within the crack tip plastic zone while the normal tensile strain increases.

2. The normal tensile stress is approximately constant inside the monotonic plastic zone at the higher values of the strain hardening exponent irrespective of the level of the applied stress.

3. With increasing the strain hardening exponent, the maximum crack tip opening displacement increases up to certain value of strain hardening exponent, above this value the effect is so much small. Such behavior was correlated.

4. Both monotonic and cyclic crack tip plastically deformed zones were found to decrease with increasing the strain hardening exponent. Such behavior was correlated.

5. A previously developed crack tip deformation parameter to correlate FCG behavior was modified to include the effect of strain hardening capacity on such behavior.

6. The results indicated that weather the fatigue crack growth and hence the life of the structural elements is controlled by the deformation at the crack tip, materials with high strain hardening exponent show low resistance to fatigue failure.

\section{REFERENCES}

1. Bruhwiler, E., Smith, I., and Hirt, M. (1990) "Fatigue and fracture of riveted bridge member", J. Struct. Engng., ASCE Vol. 116, P 198.

2. Burdekin, F. M. (1984) "Engineering design against fracture at stress concentrators", Mechanics and Physics of Fracture III, Cambridge, London, P 14.

3. Fisher, J. W. (1984) "Fatigue and fracture in steel bridges-Case studies", John Willy \& Sons, Inc., P 311.

4. Campbell, G. S. and Lahey, R. (1984) "A survey of Serious Aircraft Accidents Involving Fatigue Fracture", Int. J. Fatigue, Vol. 6, P 25.

5. Hammouda, M. M. I. and Sallam, H. E. M. (1993) "An elastic-plastic finite element simulation of crack tip deformation in fatigue", ICF8, Advances in Fracture Resistance in Material, Vol. 2, P 3.

6. Hammouda, M.M.I., Ahmad, S.S.E., and Sallam, H.E.M., (1995) "Correlation of fatigue crack growth by crack tip deformation behavior", Fatigue Fract. Engng Mater. Struct, Vol. 18, P 93.

7. Hammouda, M.M.I. El-Sehily, B.M. and De Los Rios, E.R. (1996) "The significance of crack tip deformation for short and long fatigue cracks", Fatigue Fract. Engng Mater. Struct, Vol. 19, P 475.

8. Llorca, J. and Sanchez-Galvez, V. (1989) "Influence of stress state, strain hardening and load ratio on plasticity induced fatigue crack closure", ICF7, Vol.2, P 817.

9. Ziegler, H. (1959) "A modification of Prager's Hardening Rule", Q. Appl. Math., Vol. 17.

10. Hertezberg, R. W. (1989)“ Deformation and fracture mechanics of Engineering materials" $3^{\text {rd }}$ edition, Wiley, New York. 


\title{
" تأثيّ دليل التصلد الآفعالي على عمر الأعضاء الإشثائية المصنوعة من

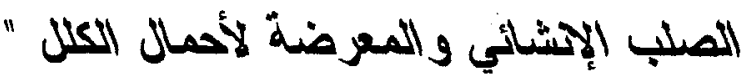

\author{
/ / محمد حسن سليم \\ قسم هندسة المواد_كلية الهندسة_ جامعة الزقازيق
}

يتعرض هذا البحث بالدر اسة النظرية باستخدام برنامج عناصر محدودة مرن-1لــــن ذات أبعـاد

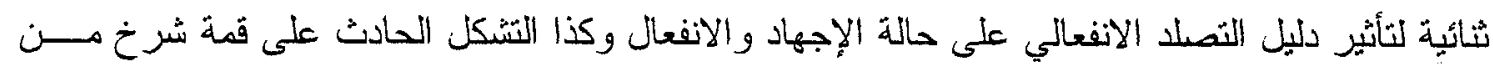

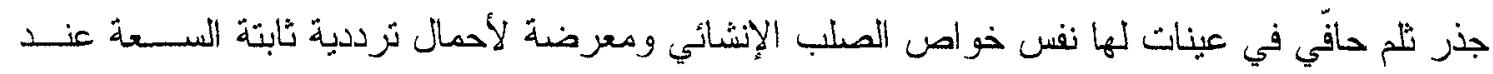
نسبة إجهاد ( أقل إجهاد / أقصى إجهاد) تساوى صفر و عند قيم مختلفة لأقصى إجهاد.

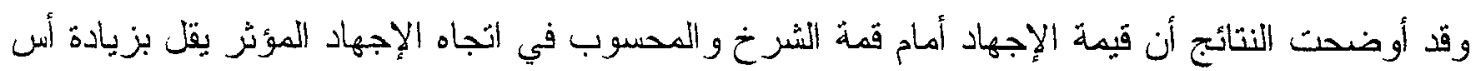

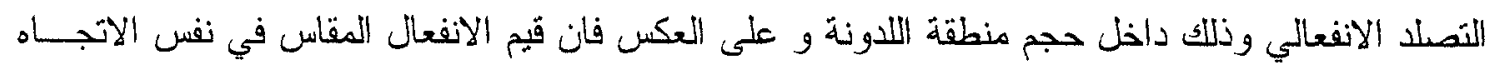

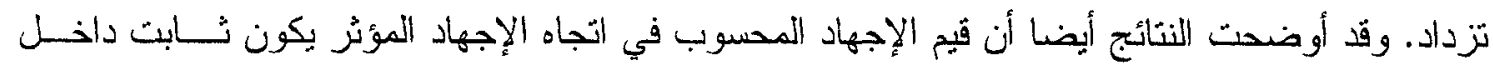

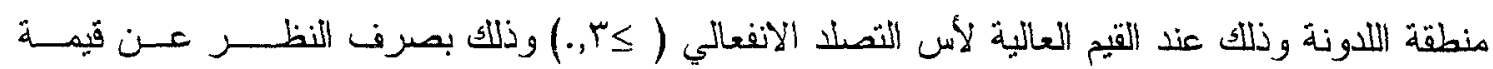

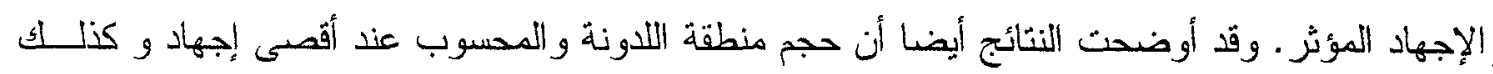

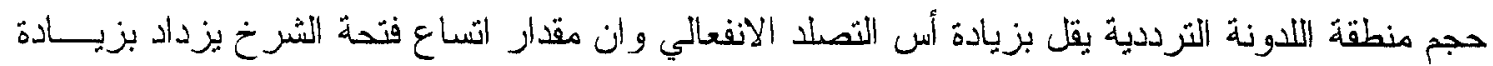

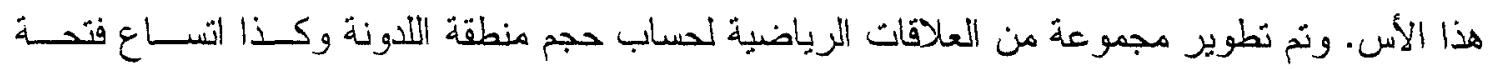

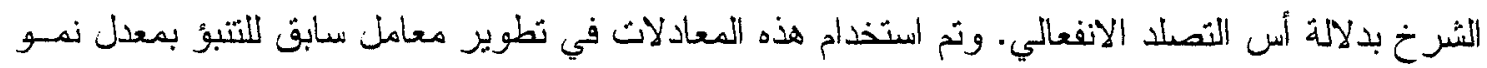

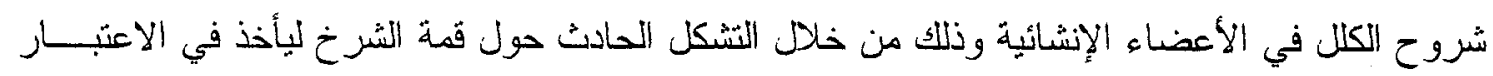
تأنير التصلا الانفعالي. 